\title{
Exploring Prospective 1-8 Teachers' Number and Operation Sense in the Context of Fractions
}

\author{
Marta T. Magiera \\ Leigh A. van den Kieboom \\ Marquette University
}

This exploratory study examined prospective elementary teachers' (PSTs') number and operation sense (NOS) in the context of solving problems with fractions. Drawing on the existing literature, we identified seven skills that characterize fraction-related NOS. We analyzed 230 responses to 23 tasks completed by 10 PSTs for evidence of PSTs' use of different fraction-related NOS skills. The analysis revealed that PSTs did not use all seven fractionrelated NOS skills to the same extent. PSTs' responses documented their frequent reasoning about the meaning of symbols and formal mathematical language in the context of fractions. To a lesser extent, PSTs' responses documented their reasoning about different representations of fractions and operations, about the composition of numbers, and about the effects of operations on pairs of fractions. We also examined possible relationships among the seven fraction-related NOS skills identified across the analyzed responses. The results reveal that some of the fraction-related NOS skills appear to support one another. Given that NOS skills provide a foundation for effective mental computation strategies, our study shows the need for explicit attention in teacher preparation programs to supporting PSTs in developing a strong awareness of and facility with a range of fraction-related NOS skills. Our study also raises questions about the relationship between PSTs' conceptual understanding of fractions and their fraction-related NOS skills and provides suggestions for future research that explores further connections among the fraction-related NOS skills.

Keywords: Fractions, mental computation, number and operation sense, prospective teachers

In many countries, the development of number and operation sense (NOS) is the desired goal for school mathematics (e.g., Australian Education Council, 1991; Common Core State Standards for Mathematics [CCSSM], 2010; National Council of Teachers of Mathematics [NCTM], 1989, 2000). The concepts and skills that characterize NOS spiral within and throughout the elementary, middle, and high school mathematics curricula. The existing mathematics education literature reflects the difficulty of defining NOS (e.g., 
Courtney-Clark \& Wessels, 2014; Greeno, 1991; Howden, 1989; Huinker 2002; McIntosh et al., 1992; Reys \& Yang, 1998; Resnick, 1989). For example, Sowder (1992) interpreted NOS as a way of thinking rather than a specific body of mathematical knowledge concerned with numbers and operations. Verschaffel et al. (2007) supported this view by describing how NOS "typifies the theme of learning mathematics as a sense-making activity" (p. 581).

Mathematics educators generally agree that NOS provides a foundation for effective mental computation strategies (e.g., Hajra \& Kofman, 2017; Threlfall, 2002). NOS is conceptualized broadly as one's general understanding of numbers and operations combined with one's ability and inclination for using this understanding in flexible ways to develop efficient strategies for solving numerical problems (e.g., Hajra \& Kofman, 2017; Reys et al., 1999). McIntosh et al. (1992) highlighted three interconnected aspects of NOS: knowledge and facility with numbers, operations, and the ability to apply knowledge of numbers and operations in computational settings. Multiple researchers emphasized these aspects of NOS, describing that students with good number sense think about numbers and operations flexibly and use sense-making (Battista et al., 2017) strategies, that is, the process of understanding ideas and concepts to identify, describe, explain, and apply them. Researchers show that students with well-developed NOS skills recognize the relationship between the context of the problem and the appropriate computation. They develop useful strategies that draw on their understanding of relationships between numbers and operations in a given context. They use benchmarks as mental referents judging the orderliness of numbers and reasonableness of calculations (Hajra \& Kofman, 2017; Heirdsfield \& Cooper, 2002; McIntosh et al., 1992; Sowder, 1988; 1992; Trafton, 1992).

K-12 students benefit when their teachers emphasize NOS strategies in computational situations. Pre-Service Teachers (PSTs) should then learn about NOS while enrolled in teacher preparation programs. In this paper, we explored NOS strategies elementary PSTs use to solve fraction-related problems. Researchers frequently draw attention to the need to support PSTs' as well as students' understanding of fraction-related concepts (Ball, 1990; Behr et al.,1986; Charalambous \& Pitta-Pantazi, 2007; Newton, 2008; Tirosh et al.,1998; Tirosh, 2000). Researchers also argue for instruction that supports students' NOS in the domain of fractions (Behr et al.,1986; Carvalho \& da Ponte, 2013). Preparing PSTs to foster NOS in their students requires a research-based understanding of PSTs' competency with the different skills that exemplify NOS. Thus, with a focus on elementary PSTs, our study examined:

1. To what extent do PSTs use different fraction-related NOS skills to solve fraction problems? 
2. What does the analysis of PSTs' responses reveal about the relationships among the different fraction-related NOS skills?

\section{Investigations into Students' and Teachers' NOS}

Research shows that students and teachers frequently have difficulty mastering NOS skills (Menon, 2004a; Reys et al., 1999; Singh, 2009; Yang et al., 2004). Reys and colleagues (1999) compared the NOS of students in Australia, Sweden, Taiwan, and the United States and reported students' NOS as overall poor. Menon (2004a) analyzed the NOS skills of U.S. elementary students from grades four to seven. When comparing performance of students in the upper and lower grades, Menon reported that students in the upper grades relied on less effective computational strategies. They predominantly used traditional paper-and-pencil computational algorithms, and infrequently considered sense-making strategies in problem-solving situations. Students in the lower grades demonstrated greater flexibility in using sense-making strategies in computational settings. Singh (2009) made similar observations when working with high school students. Like the upper grades students in Menon's study, students in Singh's study rarely used sense-making strategies in computational problem situations.

Research-based assessment of NOS demonstrated by teachers is similar to that of students (e.g., Bobis, 2004; Hajra \& Kofman, 2017; Kaminski, 1997; Menon, 2004b; Tsao, 2004, 2005; Yang et al., 2009). Several studies describe that many teachers, including PSTs, depend on procedural computational algorithms rather than sense-making strategies and have limited skills to estimate, interpret, and assess the results of computations (e.g., Hajra \& Kofman, 2017; Kaminski, 1997; Yang, 2007; Yang et al., 2009 ). It is also challenging for teachers to recognize the connections between mental strategies and procedural computational approaches (e.g., Tsao, 2004, 2005).

\section{Fractions and Fraction-Related Number and Operation Sense}

The concept of fractions encompasses multiple meanings. To understand fractions and develop fraction-related NOS, individuals have to experience fractions across many constructs, including part-whole, ratio, operator, quotient, or measure (Behr et al., 1992; Kieren, 1976; Lamon, 2007). Individuals also need to understand ways in which fractions are represented (e.g., decimals, mixed numbers, percents) and know how different forms of representing fractions relate to one another and are used to express the same quantity. Flexible understanding of the different meanings of fractions is key to estimation and mental calculation in many contexts (e.g., shopping, budgeting, concentration problems that require mixing, using scales on maps, converting among units). In this paper, while discussing fraction-related NOS, we use the term fraction to include the broad range of meanings attributed to the concept of fractions. 
McNamara and Shaughnessy (2015) described NOS for fractions as "a deep and flexible understanding of fractions that is not dependent on any one context or type of problem" (p. xiii). NOS for fractions includes the ability to flexibly reason about fractions and operations, reason and use a variety of models and representations of fractions and operations, and develop or select useful strategies for solving fraction-related problems (Courtney-Clark \& Wessels, 2014; Cramer \& Henry, 2002; Huinker, 2002; Lamon, 1999; McIntosh et al., 1992; McNamara \& Shaughnessy, 2015; Steencken \& Maher, 2002; Way, 2011, 2013).

Mathematics educators agree that the topic of fractions is one of the most difficult in the K-8 mathematics curriculum for both teachers and students (e.g., Behr et al., 1986; Carvalho \& da Ponte, 2013; Charalambous \& Pitta-Pantazi, 2007; Harvey, 2012; Kilpatrick et al., 2001; Lamon, 2007; Lobato \& Ellis, 2010). Behr and colleagues (1992) and Lamon (2007) argued that failure to construct a deep understanding of fraction concepts creates a developmental obstacle that prevents students from accessing higher-level mathematics. The multifaceted nature of fractions makes mastering different aspects of NOS with respect to fractions mathematically complex and cognitively challenging (e.g., Charalambous \& Pitta-Pantazi, 2007; Lamon, 2007).

Research literature documents difficulties PSTs have with fractionrelated concepts. For example, several studies chronicle PSTs' lack of conceptual understanding of fractions and reliance on algorithmic procedures to solve fraction problems (e.g., Ball, 1990; Chinnappan \& Forrester, 2014; Newton, 2008). Research also shows that teachers support students in developing fraction-related NOS by emphasizing the meaning of fractions rather than procedures and using mental computation strategies such as estimation and benchmarking (e.g., Charalambous \& Pitta-Pantazi, 2007; Clarke \& Roche, 2009). Teachers, including PSTs, need knowledge and facility with a wide range of skills before they can help students develop fraction-related NOS (Ma, 1999; Newton, 2008).

\section{Conceptual Framework}

We examined the existing mathematics education literature for descriptive accounts of fraction-related NOS skills (e.g., Courtney-Clark \& Wessels, 2014; Cramer \& Henry, 2002; Huinker, 2002; Lamon, 1999; McIntosh et al., 1992; Steencken \& Maher, 2002; Way, 2011, 2013). NOS skills exemplify one's ability to make sense of, that is, understand a situation, context, or concept and connect it with an existing knowledge base (Battista et al., 2017). Way (2013) highlighted three fraction-related NOS skills: recognizing visual representations of fractions, reasoning about relationships among fractions and operations, and having a sense of the magnitude of operations with fractions. Yang et al. (2009) and Courtney-Clark and Wessels 
(2014) interpreted fraction-related NOS in terms of using benchmarks for reasoning about fractions, having a sense of the relative effects of operations on fractions, and judging the reasonableness of an answer in a problem situation. In addition, Courtney-Clark and Wessels (2014) described that NOS in the domain of fractions includes the ability to reason about different representations of fractions. Huinker (2002) operationalized fraction-related NOS as the ability to reason about different models of fractions and operations, recognize operations with fractions in real-world situations, reason about the composition of numbers, and connect the use of symbols to the meaning of fractions. Table 1 summarizes fraction-related NOS skills discerned from the literature.

\section{Table 1}

Skills that Characterize ${ }^{*}$ Fraction-Related NOS

Skill

S1. Reasoning about models of fractions and operations

S2. Reasoning about specific operations with fractions in real- world situations

S3. Reasoning about the meaning of symbols and formal mathematical language in the context of fractions

S4. Reasoning about different representations of fractions and operations

S5. Reasoning about the relationships among fractions and operations with fractions

S6. Reasoning about the composition of numbers

S7. Reasoning about effects of operations on pairs of fractions
Operational Description

Using different models and sense-making strategies to represent fractions and operations with fractions in problem situations

Recognizing and selecting operations with fractions consistent with the description of the real-world problem situation

Connecting and using symbols as tools for describing the meaning for fractions and operations in problem situations

Translating among and using different representations to connect real-world, oral language, symbolic, and pictorial representations of fractions

Selecting and applying strategies that demonstrate an understanding of the relationships among fractions (including the orderliness of fractions), operations, and the properties of operations

Expressing and using fractions in equivalent forms in problem-solving situations

Selecting and applying sense-making strategies to judge the correctness and accuracy of computations

\footnotetext{
*Adapted from Cramer \& Henry (2002); Huinker (2002); Lamon (1999, 2007); Steencken \& Maher (2002)
} 


\section{Method}

\section{Participants}

The participants for this study were ten PSTs enrolled in a teacher education program at a private university in the U.S. They were all in the third year of their teacher preparation program, one year from student teaching. We conducted the study in the Number System and Operations course designed to prepare PSTs for a grades 1-8 teaching license. All PSTs previously completed a Problem Solving and Reasoning course that introduced them to a wide range of problem-solving strategies and useful ways of thinking about problem-solving situations. All PSTs enrolled in the course volunteered for their participation.

\section{Data Sources and Data Collection}

We collected the data at the beginning of a unit on fractions. We asked PSTs to respond to a series of 23 tasks selected to elicit their thinking about fractions and to examine their use of NOS skills while solving fractionrelated problems (see Table 1). The tasks were selected from course materials widely used in the U.S. for elementary teacher preparation (Beckmann, 2005; Sowder et al., 2010) that explicitly address NOS skills (see task examples in the Results section). Overall, we analyzed 230 responses (10 participants $\times 23$ tasks).

To elicit information about PSTs' NOS, we explicitly asked them to respond to each task using sense-making strategies rather than standard paperand-pencil computational algorithms. Like other researchers interested in NOS and mental computation strategies (e.g., Hajra \& Kaufman, 2017), we also asked PSTs to respond in writing and carefully document their reasoning about each task. In a way consistent with Ernest (1998), we interpreted PSTs' work as any figural or graphical representations, diagrams, numerical or symbolic representations, or written explanations. Prior research documents that individuals' strategies in written solutions do not greatly differ from those used in "think out loud" protocols. Pugalee (2001) reported that students who were asked to provide written responses did not use significantly different strategies than students who responded to the same problems by thinking aloud.

\section{Data Analysis}

\section{Qualitative Analysis}

Our data analysis was grounded in qualitative analytical-inductive methods (e.g., Miles et al., 2014; Saldaña, 2016). We first used our operational definition as a guide (see the section Conceptual Framework) to examine each response and identify fraction-related NOS skills that each PST documented in their problem solution. The identified skills were then coded using the apriori coding scheme described in Table 1. In a second round of the 
analysis, we then further examined each response to assess the extent to which PSTs used each identified skill, which we then coded as strong (score 2), emerging (score 1), or not evident (score 0 ). Both authors independently coded all PST responses and then discussed the independent results until reaching $100 \%$ agreement.

Strong NOS. We considered that a PST showed evidence of strong NOS on a given skill (score 2) if the correct solution strategy was consistent with that skill. For example, we identified a PST's knowledge of models of fractions and operations (Skill 1) as strong if the PST used a sense-making strategy rather than following a rule-based procedure. That is, they reasoned about the problem situation by developing useful models to represent the situation and embedded concepts. The model(s) they developed were effective and generated the correct solution.

Emerging NOS. On a given skill, we considered that a PST's response provided evidence of emerging NOS (score 1) if the response documented characteristics of that skill, but the sense-making strategy was not carried out correctly, leading to an incorrect result. For example, we rated a PST's performance on Skill 1, using models of fractions and operations, as emerging if the PST developed models of fractions and operations to solve a given problem, but the developed model was ineffective in supporting the correct solution. We also rated a PST's NOS as emerging with respect to a given skill if the response showed partial evidence of using that skill and partial evidence of relying on rule-based calculations. For example, we rated a PST's NOS on Skill 5, reasoning about the orderliness of fractions, as emerging if the response showed evidence that the PST used mental strategies such as benchmark fractions to reason about some fractions and relied on computational algorithms to reason about other fractions.

Not Evident NOS. We assessed that a PST did not use a NOS skill (score 0) if the solution did not include a sense-making strategy consistent with that specific skill. For example, if the response did not show any evidence that a PST reasoned about models of fractions and operations and instead documented the use of rule-based computations, we coded the response as not evident of NOS on Skill 1 (score 0).

\section{Quantitative Analysis}

For each PST, we computed his or her skill score on each of the seven fraction-related NOS skills. We defined the skill score as an average of all scores for that particular skill across the analyzed tasks. We conducted a nonparametric Friedman test to examine the distribution of median skill scores and explore the extent to which our PSTs used the different NOS skills when generating their problem solutions. To identify whether or not there were any significant differences between pairs of scores, we conducted a Wilcoxon post hoc test with a Bonferroni adjustment for multiple comparisons. We also conducted Pearson correlations to examine the relationship between each of 
the 21 pairs of scores and make inferences about possible relationships among the different NOS skills identified across PSTs' responses. We present the results of our analyses in the section that follows.

\section{Results}

Research Question 1. To what extent do PSTs use different fraction-related NOS skills to solve fraction problems?

We first discuss how PSTs used different fraction-related NOS skills in their problem solutions and illustrate their use of NOS skills with excerpts from their responses across different tasks. Then we discuss PSTs' use of the seven fraction-related NOS skills across the 230 responses by summarizing the median skill scores for each of the seven skills.

\section{Qualitative Analysis}

To illustrate PSTs' NOS on three skills: Skill 1-reasoning about models of fractions and operations; Skill 2- reasoning about specific operations with fractions in real-world situations; and Skill 4-reasoning about different representations of fractions and operations, we use the following problem: Ken ordered $\frac{4}{5}$ of a ton of sand. Ken wants to receive $\frac{1}{3}$ of his order now and $\frac{2}{3}$ of his order later. What fraction of a ton of sand should Ken receive now? Show and explain your reasoning.

Included in Figures 1 and 2 are excerpts from two PSTs' responses to illustrate our assessment of their NOS skills on this problem.

\section{Figure 1}

PST \#9'sRresponse

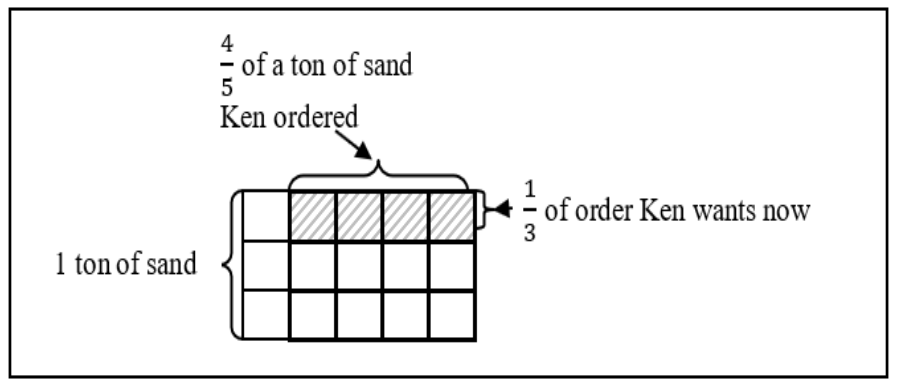

Responses from PST \#9 (see Figure 1) and PST \#1 (see Figure 2) show that they used sense-making strategies while reasoning about the meaning of fractions represented in this problem situation. Both PSTs used effective models through which they revealed reasoning about the part-whole meaning of fractions in this problem (Skill 1). Consistent with our coding schema, we assessed both responses as documenting strong (score 2) NOS on 
Skill 1. The models also show that each PST recognized and reasoned about the connections between the real-world situation depicted in the problem and specific operations with fractions (Skill 2). We assessed both responses as evidence of strong NOS on Skill 2, connecting real-world situations with specific operations on fractions, specifically in this problem, showing PSTs' understanding of multiplication of fractions. We also believe that both responses document PSTs' flexibility with different representations of fractions and ability to translate among these representations (Skill 4) effectively. The labeling of their respective diagrams provides evidence that each PST connected the verbal descriptions of the problem situation, the pictorial models they constructed for that situation, the meaning of fractions and operations they recognized in the problem situation, and the symbols they used. Each response then also provides evidence of strong NOS on Skill 4.

\section{Figure 2}

PST \#1's Response

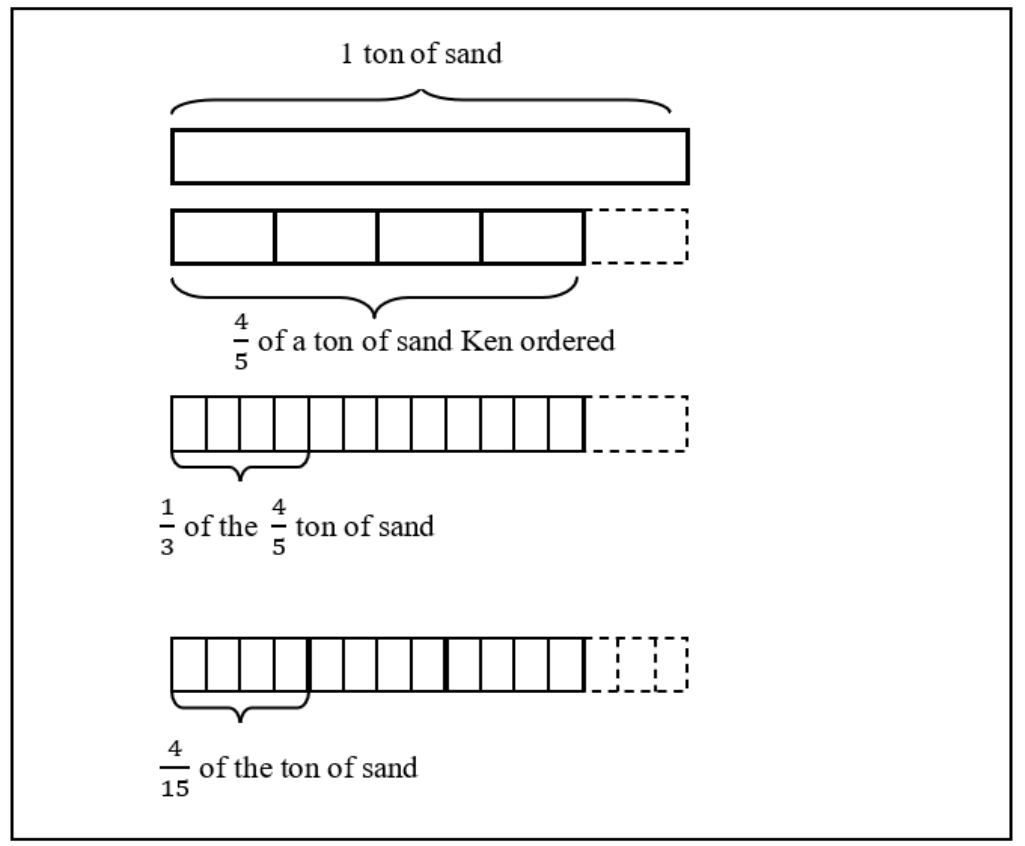

To illustrate PSTs' NOS on Skill 5-reasoning about the relationships among fractions and operations with fractions, we use the following task: Sort fractions below into three groups: Fractions that are about zero, fractions that are about $\frac{1}{2}$ and fractions that are about $1 . \frac{1}{10}, \frac{2}{3}, \frac{1}{5}, \frac{1}{7}, \frac{1}{3}, \frac{5}{9}, \frac{9}{11}, \frac{3}{10}, \frac{2}{5}, \frac{2}{12}, \frac{1}{9}$, $\frac{2}{7}, \frac{22}{50}, \frac{7}{9}, \frac{8}{15}, \frac{4}{10}, \frac{22}{25}, \frac{5}{8}, \frac{13}{30}, \frac{5}{6}$. Clearly explain your thinking.

Consider the response included in Figure 3. Figure 3 shows how PST \#9 makes sense of and reasons about the orderliness and relationships among 
fractions. Even though she was unable to make adjustments to her strategy to decide whether $\frac{2}{3}$ should be considered as being about $\frac{1}{2}$ or about 1 , her explanation documents reasoning about the relative magnitude of fractions using benchmark fractions as mental referents. We considered her explanations as evidence of strong (score 2) NOS on Skill 5.

We use the task: The price of a blouse was first reduced by $25 \%$ and then reduced by $20 \%$ (from already reduced price). What if instead, the blouse had first been reduced by $20 \%$ and then by $25 \%$ (from the reduced price)? Would the final price still be the same, higher or lower? Explain to illustrate PSTs' NOS on Skill 5 further. We also use this problem to illustrate PSTs' NOS on Skill 7 - reasoning about the effects of operations on pairs of fractions. Consider the responses included in Figures 4 and 5.

\section{Figure 3}

PST \#9's Response

Fractions which are about zero: I first put into this pile all fractions that had opposite numerators and denominators. 1 and 9 in $\frac{1}{9}$ are the two farthest apart numbers from one another across the spectrum.

Therefore, how I decided which fractions went where was through a careful comparison of the numerator and denominator. If the numerator was closer to zero than the half or whole mark it [the fraction] was placed into about "zero" category.

Fractions which are about half: This I feel was the trickiest because there was much variance between which fractions were included. Once again I used the tactic of comparing numerators and denominators to see which fractions fit here. For these, I first looked at the denominator and figured out what its actual half would be. If the denominator's actual half was close to the actual numerator it was put in this group. The dominator's actual half and the actual numerator had to be within the range difference of $\frac{1}{2}$ to 2 to be placed in this category.

Fractions which are about 1: These fractions got placed in this group because they were also compared by the difference between the numerator and the true denominator. If the numerators were much closer to the true denominator and not its half it was placed in this pile.

The only issue I had was $\frac{2}{3}$ because it seems to fit in both the $\frac{1}{2}$ and the 1 category. I just put it into both because of the rules I had established. 


\section{Figure 4}

PST \#2's Response

Scenario 1: $(\mathrm{B} \times 25 \%) \times 20 \% \quad$ Scenario $2:(\mathrm{B} \times 20 \%) \times 25 \%$

The final price of the blouse in the second and the first scenario would be the same. The price would be the same because of the commutative property. The order does not affect multiplication problem outcomes. In both scenarios you are finding $20 \%$ and $25 \%$ off, of the blouse price. The order does not matter.

Presented in Figure 4 PST \#2's explanation, "The final price of the blouse in the second and the first scenario would be the same ... The order does not affect multiplication problem outcomes," shows that she engaged in thinking about the relationships among numbers and properties of operations (Skill 5). PST \#2's strategy documents her reasoning about properties of operations-we assessed her response as evidence of strong (score 2) NOS on Skill 5. PST \#2 considered the total discount and judged the effects of operations without actually performing operations in this problem situation. Because PST \#2 documented that she reasoned about and judged the effects of operations on pairs of fractions, we also assessed her response as evidence of strong (score 2) NOS on Skill 7.

As an illustration of an emerging (score 1) NOS on Skill 5 and not evident NOS (score 0) on Skill 7, consider the response of PST \#5 included in Figure 5.

Figure 5

PST \#5's Response

Assume the blouse was $\$ 10$.

$25 \%$ off: $0.75 \times$ original price: $0.75 \times \$ 10=\$ 7.50$

$20 \%$ off: $0.80 \times$ discount price: $0.80 \times \$ 7.50=\$ 6$

Original price $\$ 10$.

$20 \%$ off: $0.80 \times 10=\$ 8$

$25 \%$ off: $0.75 \times$ discount price: $0.75 \times \$ 8=\$ 6$

The blouse [price] will stay always the same as long as \% reduction will be the same (not meaning the same order but the same \%). To find the price of the dress [blouse] you take original price and times [by] what percent is left ( $25 \%$ off is $75 \%$ left to pay) and repeat for next $\%$ off. This gives you $a \cdot b \cdot c=a \cdot c \cdot b$ so the commutative property is used here.

Unlike PST \#2, who reasoned about the relationships among numbers and effects of operations without computing, PST \#5 determined the answer by conducting case-based calculations and comparing their results. PST \#5 assumed the initial value of the quantity described in the problem. She 
recognized the relationship between the discount price and the price paid given her assumed initial value and explored both problem scenarios. PST \#5 reflected on the results of her calculations and then identified the relevant property involved. Consistent with our scoring rubric, we interpreted her response as evidence of emerging (score 1) NOS on Skill 5. Given that to judge the effects of operations, PST \#5 needed to compute and compare the results of her calculations, we also assessed this response as not indicative of NOS on Skill 7 (score 0).

Consider the task: Mark says that $\frac{11}{12}=\frac{16}{17}$ because both fractions are one away from the whole. Is he correct? If yes, explain why. If not, explain what is wrong with his reasoning as a context for discussing PSTs' NOS on Skill 3-reasoning about the meaning of symbols and formal mathematical language in the context of fractions. We illustrate PSTs' use of this skill with PST \#1's response included in Figure 6.

As illustrated in Figure 6, in this problem situation, PST \#1 was making sense of the fraction symbol and the phrase "one away from the whole," Skill 3. Her explanation demonstrates her understanding of the meaning of the fraction symbol and the part-whole relationship. It also documents that while comparing the fractions $\frac{1}{12}$ and $\frac{1}{17}$ PST \#1 effectively reasoned about relationships among fractions and the orderliness of fractions, Skill 5. We assessed her NOS on both skills as strong (score 2).

\section{Figure 6}

PST \#1's Response

Mark is not correct because even though both fractions are one away from the whole that one is not equivalent in both fractions. $\frac{11}{12}$ expresses a fraction of a whole in twelfths whereas $16 / 17$ does so in seventeenths. Because there are more seventeenths needed to make a whole than twelfths (you need 17 seventeenths to make a whole but only 12 twelfths to make the same whole) a seventeenth is smaller than a twelfth. Both of these fractions are "one away" from one whole, however, because the "one" in $\frac{17}{17}$ (or $\left.\frac{1}{17}\right)$ is smaller than the "one" in $\frac{12}{12}\left(\frac{1}{12}\right)$, there is more of the fraction expressed in seventeenths present with only one piece missing than there is of the fraction expressed in twelfths. Therefore, $\frac{11}{12}<\frac{16}{17}$.

Finally, we illustrate how PSTs used NOS Skill 6- reasoning about the composition of numbers, using the task: Mary has to calculate $\frac{2}{3} \times 6 \frac{3}{4}$. She does not want to convert $6 \frac{3}{4}$ to an improper fraction. Explain how she can solve the problem. 
Figure 7

PST \#1's Response

$$
\begin{aligned}
\frac{2}{3} \cdot 6 \frac{3}{4} & =\frac{2}{3} \cdot\left(6+\frac{3}{4}\right) \quad \text { She can break } 6 \frac{3}{4} \text { and multiply both parts by } \frac{2}{3} . \text { This is } \\
& =\frac{2}{3} \cdot 6+\frac{2}{3} \cdot \frac{3}{4} \quad \text { distributive property of multiplication over addition. } \\
& =\frac{12}{3}+\frac{6}{12} \\
& =4+\frac{1}{2} \\
& =4 \frac{1}{2}
\end{aligned}
$$

For example, consider the response included in Figure 7 as an example of strong (score 2) NOS on Skill 6. PST 1's solution (see Figure 7) shows her understanding of equivalent forms of fractions, her facility with the composition and decomposition of fractions, and her thinking about properties of operations.

\section{Quantitative Analysis}

To further illustrate PSTs' use of different fraction-related NOS skills across the 230 analyzed responses, we summarize median skill scores (see Table 2). We also provide a visual of the overall distribution of skill scores in Figure 8.

We conducted a Friedman's test to compare the median fractionrelated NOS skill scores for the seven skills of interest. The test was significant at the 0.05 level, $\chi^{2}(6, \mathrm{~N}=10)=13.08, p=0.032$. Kendall's coefficient of concordance of 0.23 indicated fairly large differences in PSTs' performance across the seven skills. A Wilcoxon test with Bonferroni adjustment for multiple comparisons confirmed significant differences between the following pairs of skills: (S1 \& S7), $z=2.510, p=0.012$; (S3 \& S6), $z=2.516, p=0.031$; and (S3 \& S7), $z=2.680, p=0.007$. The other differences were not statistically significant.

As illustrated in Table 2 and Figure 8, PSTs' performance on Skill 3 (reasoning about the meaning of symbols and formal mathematical language in the context of fractions) was the strongest. Across all responses, $50 \%$ of the PSTs provided evidence of strong use of Skill 3. In contrast, PSTs' demonstrated the weakest NOS on Skill 4 (reasoning about different representations of fractions and operations), Skill 6 (reasoning about the composition of numbers), and Skill 7 (reasoning about effects of operations on pairs of fractions). We hypothesize that these results might relate to the nature of PSTs' understanding of the multifaceted fraction-related concepts and further discuss our conjecture in the section that follows. 


\section{Table 2}

\section{Median Skill Scores}

\begin{tabular}{lcc}
\hline Skill & $n^{*}$ & $\begin{array}{c}\text { Median Skill Score } \\
\text { (N = 10) }\end{array}$ \\
\hline $\begin{array}{l}\text { S1. Reasoning about models of fractions and operations } \\
\begin{array}{l}\text { S2. Reasoning about specific operations with fractions in } \\
\text { real-world situations }\end{array}\end{array}$ & 12 & 1.71 \\
$\begin{array}{l}\text { S3. Reasoning about the meaning of symbols and formal } \\
\text { mathematical language in the context of fractions }\end{array}$ & 3 & 2.00 \\
$\begin{array}{l}\text { S4. Reasoning about different representations of fractions } \\
\text { and operations }\end{array}$ & 10 & 1.40 \\
$\begin{array}{l}\text { S5. Reasoning about the relationships among fractions and } \\
\text { operations with fractions }\end{array}$ & 4 & 1.75 \\
$\quad \begin{array}{l}\text { S6. Reasoning about the composition of numbers } \\
\text { S7. Reasoning about effects of operations on pairs of } \\
\text { Fractions }\end{array}$ & 3 & 1.33 \\
\hline$n^{*}$ Number of tasks that fostered strategies consistent with a given skill &
\end{tabular}

\section{Figure 8}

Distribution of PSTs' Skill Scores on the Seven NOS Skills Related to Fractions

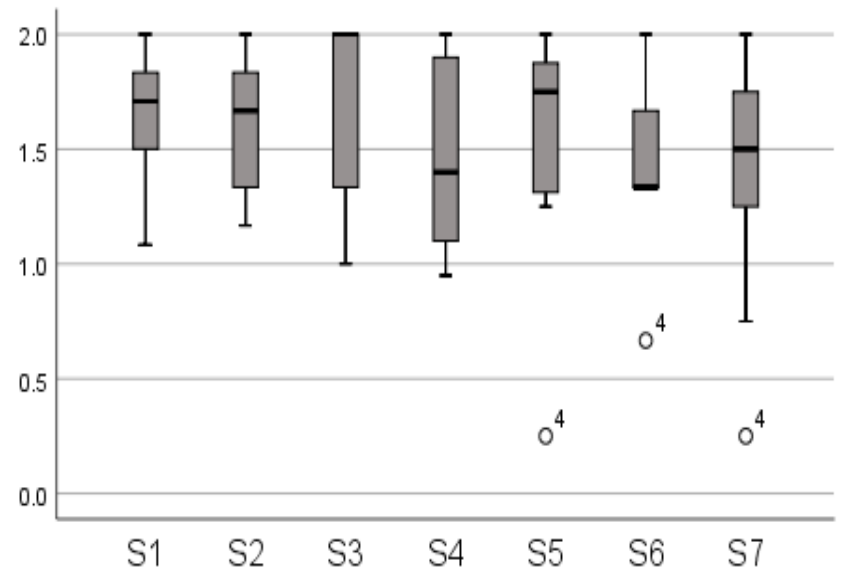

Research Question 2. What does the analysis of PSTs' responses reveal about the relationships among the different fraction-related NOS skills? 
Included in Table 3 are pair-wise correlations (Pearson) among the NOS skill scores. The identified correlation patterns among the pairs of scores are illustrated in Figure 9.

The analysis revealed that out of the 21 possible correlation pairs, ten were non-zero correlations. All ten correlation scores were within the critical region $(-0.576 ; 0.576, \alpha=0.05)$ for our sample size $(n=10)$, allowing us to conclude that the observed associations are independent of our sample of PSTs.

Strong and positive associations were identified among Skill 1and Skills 3, 4, 5, 6, and 7. Correlations between Skill 1 and Skills 3 and 7 were significant, with $p<0.01$ and their respective values were $r=0.80,(1 \& 3)$ and $r=0.94,(1 \& 7)$ (see Table 3). Correlations between Skill 1 and Skills 4, 5 , and 6 were significant with, $p<0.05$ and their respective values were $r=$ $0.74,(1 \& 4) ; r=0.65,(1 \& 5)$; and $r=0.68,(1 \& 6)$. The pattern also showed strong positive correlations between Skills 3 and 5, $r=0.64$, p $<0.05$; Skills 3 and 7, $r=0.88, p<0.01$; Skills 4 and $6, r=0.70, p<0.05$; Skills 5 and 7, $r$ $=0.64 p<0.05$; and Skills 6 and 7, $r=0.74, p<0.05$. Skill 2, (reasoning about specific operations with fractions in real-world situations), however, appeared to be independent of other skills characterizing fraction NOS. None of the correlations that involved Skill 2 were statistically significant.

\section{Table 3}

Correlation Matrix for the Seven Fraction-Related NOS Skills

\begin{tabular}{|c|c|c|c|c|c|c|c|}
\hline Skills & S1 & S2 & S3 & S4 & S5 & S6 & S7 \\
\hline $\begin{array}{l}\text { S1. Reasoning about models of fractions } \\
\text { and operations }\end{array}$ & - & & & & & & \\
\hline $\begin{array}{l}\text { S2. Reasoning about specific operations with } \\
\text { fractions in real-world situations }\end{array}$ & 0.40 & - & & & & & \\
\hline $\begin{array}{l}\text { S3. Reasoning about the meaning of symbols } \\
\text { and formal mathematical language in } \\
\text { the context of fractions }\end{array}$ & $0.80 * *$ & -0.37 & - & & & & \\
\hline $\begin{array}{l}\text { S4. Reasoning about different representations } \\
\text { of fractions and operations }\end{array}$ & $0.74 *$ & 0.59 & 0.30 & - & & & \\
\hline $\begin{array}{l}\text { S5. Reasoning about the relationships among } \\
\text { fractions and operations with } \\
\text { fractions }\end{array}$ & $0.65 *$ & -0.17 & $0.64 *$ & 0.54 & - & & \\
\hline $\begin{array}{l}\text { S6. Reasoning about the composition of } \\
\text { numbers }\end{array}$ & $0.68 *$ & 0.38 & 0.53 & $0.70 *$ & 0.62 & - & \\
\hline $\begin{array}{l}\text { S7. Reasoning about effects of operations } \\
\text { on pairs of fractions }\end{array}$ & $0.94 * *$ & -0.03 & $0.88 * *$ & 0.61 & $0.64 *$ & $0.74 *$ & - \\
\hline
\end{tabular}

\section{Figure 9}

Correlation Patterns Among the Seven NOS Skills in the Domain of Fractions 


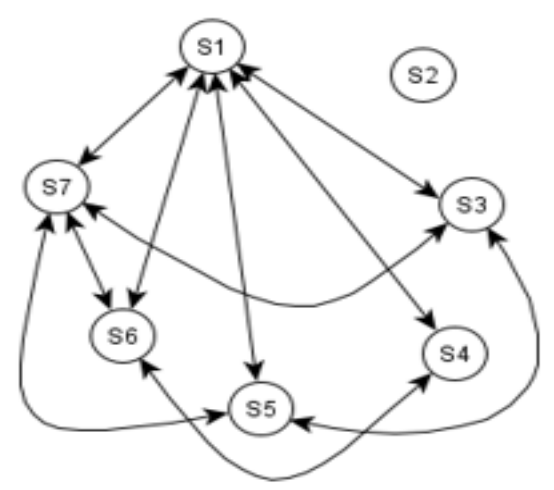

\section{Discussion and Implications}

The results of past studies document the importance of supporting PSTs' in making sense of numbers and operations, particularly in the domain of fractions (Ball, 1990; Ma, 1999; Newton, 2008; Tirosh, 2000; Tirosh et al., 1998). Research shows that PSTs generally struggle while solving fractionrelated problems and often rely on paper-and-pencil computational procedures rather than sense-making strategies (e.g., Ball, 1990; Harvey, 2012; Newton, 2008; Tirosh, 2000; Tirosh et al., 1998). Our work extended prior studies on PSTs' knowledge of fractions by exploring the extent to which PSTs use different NOS skills in the context of solving problems with fractions. We also examined possible associations among NOS skills identified in PSTs' problem solutions. Our research shows that PSTs do not use all NOS skills to the same extent while solving fraction-related problems, suggesting the need to build their awareness of and facility with a range of fraction-related NOS skills. Our work also draws attention to the possible connections among NOS skills in the context of fractions.

Among the seven fraction-related NOS skills we investigated, our PSTs' showed the greatest facility with recognizing the meaning of symbols and formal mathematical language in the context of fractions (Skill 3). In contrast, our PSTs least frequently reasoned about different representations of fractions and operations (Skill 4), about the composition of numbers (Skill 6), and about the effects of operations on pairs of fractions (Skill 7).

To effectively support students in developing flexibility with fractions and operations that supports mental computations, PSTs need knowledge of and facility with a wide range of fraction-related NOS skills. Our results highlight the need to build PSTs' awareness of and support their expertise and facility with a broad range of fraction-related NOS skills. Compared with the other six skills, our PSTs' greater use of Skill 3 (reasoning about the meaning of symbols and formal mathematical language in the context of fractions) might not be surprising. Past research on PSTs' knowledge of 
fractions shows that PSTs often rely on paper-and-pencil algorithms while solving problems with fractions (e.g., Harvey, 2012; Newton, 2008; Tirosh, 2000). Thus, the greater use of Skill 3 might suggest that PSTs in our study relied more on their procedural than a conceptual understanding of fractionrelated concepts. Like some mathematics education researchers (e.g., Heirdsfield, 2003; Heirdsfield \& Cooper, 2002), we believe that NOS skills, such as reasoning about equivalent fractions, different representations of fractions, or judging computational results, are grounded in conceptual rather than procedural understanding. For example, to make sense of the validity of a specific result of fraction division, one would need to understand the meaning of the division of fractions in a given context. That is, one would need to understand that division might generate a result that is larger or smaller, depending on the situation. One would also need a conceptual understanding to make sense of different representations of fractions and fluently translate among them. Without having a complex understanding of fraction-related concepts, one, for example, might not be able to flexibly think about the pictorial model below (Figure 10) as possibly representing $\frac{1}{4}, \frac{3}{12}$, or $\frac{3}{9}$.

\section{Figure 10}

Pictorial model of $\frac{1}{4}, \frac{3}{12}$, or $\frac{3}{9}$

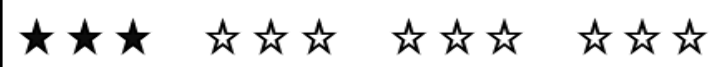

In our study, we asked PSTs to reason about the given problems using sensemaking strategies without first assessing the level of PSTs' conceptual or procedural understanding of fractions. Further research then needs to examine our hypothesis about possible connections between fraction-related NOS and individuals' conceptual understanding of the construct of fractions.

Our results document groups of fraction-related NOS skills that might possibly support one another. This group of supporting skills includes Skills 1, 3, 5, and 7 (see Figure 9). And, to a lesser degree, since no correlation existed between Skills 4 and 7, a group formed by Skills 1, 4, 6, and 7 (see Figure 9). Our data also showed a lack of apparent association between the PSTs' use of Skill 2 (reasoning about specific operations with fractions in real-world situations) and the remaining six fraction-related NOS skills. None of the correlations that involved Skill 2 were statistically significant.

Our exploratory study only begins to sort out the possible connections among PSTs' fraction-related NOS skills, and we recognize that the generalizability of our study might be limited. Further research with a greater number and more diverse group of PSTs, a broader selection of tasks, different instructional settings, and follow-up interviews could strengthen 
what we uncovered about our PSTs' use of fraction-related NOS skills. More research that identifies groups of skills that could be targeted concurrently and those requiring explicit instructional attention can guide the design of classroom activities that strengthen PSTs' NOS in the domain of fractions. Thus we believe that our study provides a promising direction for further research and suggests paths for mathematics education researchers to pursue.

\section{References}

Australian Education Council. (1991). A national statement on mathematics for Australian schools. A joint project of the States, Territories and the Commonwealth of Australia, Australian Education Council, https://eric.ed.gov/?id=ED428947.

Ball, D. L. (1990). The mathematical understanding that prospective teachers bring to teacher education. Elementary School Journal, 90(4), 449466.

Battista, M., Baek, J, Cramer, K., \& Blanton, M. (2017). Reasoning and sense-making in the elementary grades, grades 3-5. NCTM.

Beckmann, S. (2011). Mathematics for elementary school teachers with activity manual $\left(3^{\text {rd }}\right.$ Ed.). Addison-Wesley. Pearson Education.

Behr, M. J., Harel, G., Post, T., \& Lesh, R. (1992). Rational number, ratio, and proportion. In Grouws, D. (Ed.), Handbook of research on mathematics teaching and learning (pp. 296-333). National Council of Teachers of Mathematics.

Bobis, J. (2004). Number sense and the professional development of teachers. In A. McIntosh \& L. Sparrow (Eds.), Beyond written computation (pp. 160-170). Mathematics, Science \& Technology Education Centre, Edith Cowan University.

Carvalho, R., \& da Ponte, J. P. (2013). Students' mental computation strategies with fractions. In B. Ubuz, C. Haser, \& M. A. Mariotti (Eds.). Proceedings of the eight congresses of the European Society for Research in Mathematics Education. (pp. 283-292). Middle East Technical University, Ankara, Turkey.

Charalambous C. Y., \& Pitta-Pantazi, D. (2007). Drawing on a theoretical model to study students' understandings of fractions. Educational Studies in Mathematics, 64(3), 293-316.

Chinnappan, M., \& Forrester, P. (2014). Generating procedural and conceptual knowledge of fractions by pre-service teachers. Mathematics Education Research Journal, 26, 871-896.

Clarke, D., \& Roche, A. (2009). Students' fraction comparison strategies as a window into robust understanding and possible pointers for instruction. Educational Studies in Mathematics, 72, 127-138. 
Common Core State Standards for Mathematics [CCSSM]. (2010). National Governor's Association (NGA) \& Council of Chief State School Officers

(CCSSO). http://www.corestandards.org/assets/CCSSI_Math\%20Standards.pdf.

Courtney-Clarke, M., \& Wessels, H. (2014). Number sense of final year preservice primary teachers. Pythagoras, 35(1), 1-9. http://dx.doi.org/10.4102/pythagoras.v35i1.244

Cramer, K., \& Henry, A. (2002). Using manipulative models to build number sense for addition of fractions. In B. Litwiller \& G. Bright (Eds.). Making sense of fractions, ratios and proportions. (pp. 41-48). 2002 Yearbook, National Council of Teachers of Mathematics, Reston, WA.

Ernest, P. (1998). Social constructivism as a philosophy of mathematics, SUNY Press.

Greeno, J. (1991). Number sense as situated knowing in a conceptual domain. Journal for Research in Mathematics Education, 22(3), 170-218.

Hajra, S. G., \& Kofman, V. (2017). The effects of mental math strategies on pre-service teachers' self-awareness and computational skills. Journal of Mathematics Education, 10(1), 92-108.

Harvey, R. (2012). Stretching student teachers' understanding of fractions. Mathematics Education Research Journal, 24, 493-511. DOI 10.1007/s13394-012-0050-7.

Heirdsfield, A. M. (2003). Spontaneous mental computation strategies. In N. A. Pateman, B. J. Dougherty, J. T. \& Zilliox (Eds.). Proceedings of the $27^{\text {th }}$ Conference of the International Group for the Psychology of Mathematics Education (pp. 55-62). University of Hawaii.

Heirdsfield, A. M., \& Cooper, T. J. (2002). Flexibility and inflexibility in accurate mental addition and subtraction: Two case studies. Journal of Mathematical Behavior, 21, 57-74.

Howden, H. (1989). Teaching number sense. Arithmetic Teacher, 36(6), 6-11.

Huinker, D. (2002). Examining dimensions of fraction operations sense. In B.

Litwiller \& G. Bright (Eds.). Making sense of fractions, ratios and proportions. (pp. 72-78). 2002 Yearbook, National Council of Teachers of Mathematics,.

Kaminski, E. (1997). Teacher education students' number sense: Initial explorations.Mathematics Education Research Journal, 9(2), 225-235.

Kieren, T. (1976). On the mathematical cognitive and instructional foundations of rational numbers. In R. Lesh (Ed.). Number and measurement: Papers from a research workshop (pp. 101-144). ERIC/SMEAC.

Kilpatrick, J., Swafford, J., \& Findell, B. (Eds.). (2001). Adding it up: Helping children learn mathematics. National Academy Press.

Lamon, S. J. (1999). Teaching fractions and ratios for understanding. Essential content knowledge and instructional strategies for teachers. Lawrence Erlbaum Associates.. 
Lamon, S. J. (2007). Rational numbers and proportional reasoning: Toward a theoretical framework for research. In Lester, F. (Ed.), Second handbook of research on teaching and learning mathematics (pp. 157223). National Council of Teachers of Mathematics.

Lobato, J., \& Ellis, A. (2010). Developing essential understanding of ratios, proportions, and proportional reasoning for teaching mathematics: Grades 6-8. National Council of Teachers of Mathematics.

Ma, L. (1999). Knowing and teaching elementary mathematics: Teachers' understanding of fundamental mathematics in China and the United States. Erlbaum.

McIntosh, A., Reys, B. J., \& Reyes, R. E. (1992). A proposed framework for examining the basic number sense. For the Learning of Mathematics, 12(3), 2-8.

McNamara, J., \& Shaughnessy, M. M. (2015). Beyond pizzas \& pies, Grades 3-5: 10 Essential Strategies for Supporting Fraction Sense. (2nd ed.). Math Solutions Publications.

Menon, R. (2004a). Elementary school children's number sense. International Journal for Mathematics Teaching and Learning, http://www.cimt.org.uk/ijmtl/index.php/IJMTL.

Menon, R. (2004b). Preservice teachers' number sense. Focus on Learning Problems in Mathematics, 26(2), 49-61.

Miles, M. B., Huberman, A. M., \& Saldaña, J. (2014). Qualitative data analysis: A methods sourcebook ( $3^{\text {rd }}$ Ed.). Sage.

National Council of Teachers of Mathematics (1989). Curriculum and evaluation standards for school mathematics. NCTM. Author.

National Council of Teachers of Mathematics (2000). Principles and standards forschool mathematics.. Author.

Newton, K. J. (2008). An extensive analysis of preservice teachers' knowledge of fractions. American Educational Research Journal, 45(4), 1080-1110.

Pugalee, D. (2001). Writing, mathematics and metacognition: Looking for connections through students' work in mathematical problem solving. School Science and Mathematics, 101(5), 236-245.

Resnick, L. (1989). Defining, assessing and teaching numbers sense. In J. T. Sowder \& B. P. Schappelle (Eds.). Establishing foundations for research on numbers sense and related topics: Report of a conference (pp.1-15). San Diego State University.

Reys, R., Reys, B., McIntosh, A., \& Emanuelsson, G., Johansson, B., \& Yang, D. C. (1999). Assessing number sense of students in Australia, Sweden, Taiwan, and the United States. School Science and Mathematics, 99(2), 61-70.

Reys, R., \& Yang, D. (1998). Relationship between computational performance and number sense among sixth and eighth-grade students in Taiwan. Journal for Research in Mathematics, 29(2), 225-237. 
Saldaña, J. (2016). The coding manual for qualitative researchers.Sage Publications Inc.

Singh, P. (2009). An assessment of number sense among secondary school students. International Journal for Mathematics Teaching and Learning, http://www.cimt.org.uk/ijmtl/index.php/IJMTL

Sowder, J. (1988). Mental computation and number comparison: Their roles in the development of number sense and computational estimation. In Hiebert \& Behr (Eds.). Research Agenda for Mathematics Education: Number Concepts and Operations in the Middle Grades (pp. 192-197). Lawrence, Erlbaum \& Reston.

Sowder, J. (1992). Estimation and number sense. In D. Grouws (Ed.) Handbook of research on mathematics teaching and learning (pp.371389). Macmillan.

Sowder, J., Sowder, L., \& Nickerson, S. (2017). Reconceptualizing mathematics for elementary school teachers. ( ${ }^{\text {rd }}$ Ed.). W.H. Freeman and Company.

Steencken, E., \& Maher, C. (2002). Young children's growing understanding of fraction ideas. In B. Litwiller, \& G. Bright (Eds.). Making sense of fractions, ratios and proportions, 2002 Yearbook of the National Council of Teachers of Mathematics (pp.49-60). NCTM.

Tirosh, D. (2000). Enhancing prospective teachers' knowledge of children's conceptions: The case of division of fractions. Journal for Research in Mathematics Education, 31(1), 5-25.

Tirosh, D., Fischbein, E., Graeber, A. O., \& Wilson, J. W. (1998). Prospective elementary teachers' conceptions of rational numbers. http://jwilson.coe.uga.edu/Texts.Folder/Tirosh/Pros.El.Tchrs.html.

Trafton, P. (1992). Using number sense to develop mental computation and computational estimation. In C. Irons (Ed.) Challenging children to think when they compute (pp. 78-92). Queensland University of Technology, Centre for Mathematics and Science Education.

Threlfall, J. (2002). Flexible mental calculation. Educational Studies in Mathematics, 50(1), 29-47.

Tsao, Y. L. (2004). Exploring the connections among number sense, mental computation performance, and the written computation performance of elementary preservice teachers. Journal of College Teaching and Learning, 1(12), 71-90.

Tsao, Y. L. (2005). The number sense of preservice elementary teachers, College Student Journal, 39(4), 647-678.

Yang, D. C. (2007). Investigating the strategies used by pre-service teachers in Taiwan when responding to number sense questions, School Science and Mathematics, 107 (7), 293-301.

Yang, D. C., Hsu, C. J., \& Huang, M. C. (2004). A study of teaching and learning number sense for sixth grade students in Taiwan. 
International Journal of Science and Mathematics Education, 2 (3), 407-430.

Yang, D. C., Reys, R. E., \& Reys, B. J. (2009). Number sense strategies used by pre-service teachers in Taiwan. International Journal of Science and Mathematics Education, 7(2), 383-403.

Verschaffel, L., Greer, B., \& DeCorte, B. (2007). Whole number concepts andoperations. In F. Lester (Ed.), The Handbook of research on mathematics teaching and learning ( $\left.2^{\text {nd }} e d.\right)$, (pp. 557-628). National Council of Teachers of Mathematics: Information Age Publishing.

Way, J. (2011). Developing number sense using learning objects. In J., Way, \& J., Bobis (Eds.), Fractions: Teaching for understanding (pp.153166). The Australian Association of Mathematics Teachers (AAMT) Inc.

Way, J. (2013). AAMT - Top drawer teachers resource: Fractions. Retrieved from https://topdrawer.aamt.edu. au/Fractions/Goodteaching/Fraction-sense/Fractions-as-numbers.

\section{Authors:}

Marta T. Magiera (corresponding author)

Marquette University

Department of Mathematical and Statistical Sciences

P.O. Box 1881

Cudahy Hall \#330

Milwaukee, WI 53201-1881, USA

Tel: 414-288-6597

e-mail: marta.magiera@marquette.edu

Leigh A. van den Kieboom

Marquette University

College of Education

P.O. Box 1881

Walter Schroeder Health Complex \#113h

Milwaukee, Wisconsin 53201-1881, USA

Tel: 414-288-1429

e-mail: leigh.vandenkieboom@mu.edu 